\title{
Complementary data
}

Fig.1 Hydrodynamic diameter of microgel in temperature range of $10-50{ }^{\circ} \mathrm{C}$.

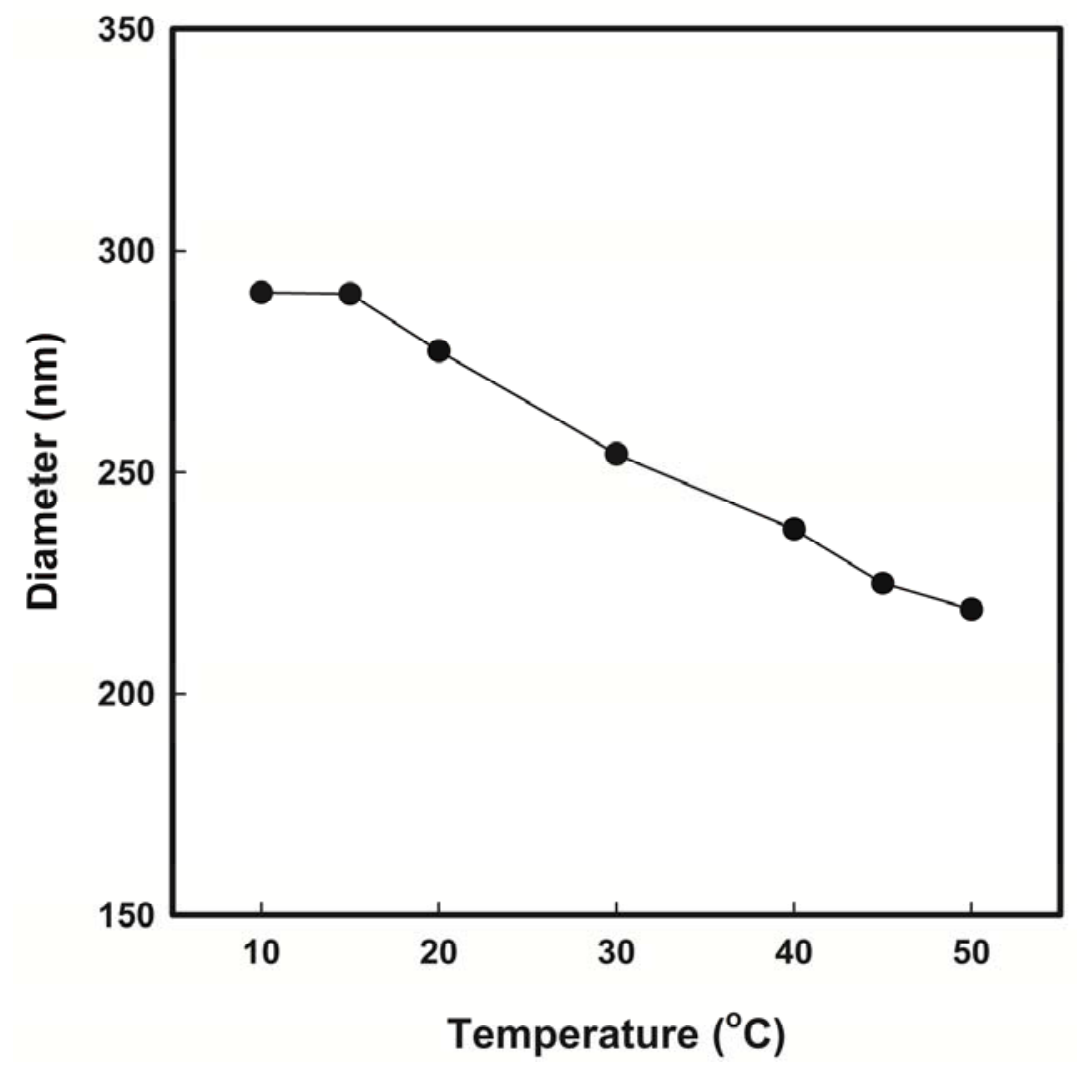


Fig.2 The molar extinction coefficient of cinnamic acid (CA).

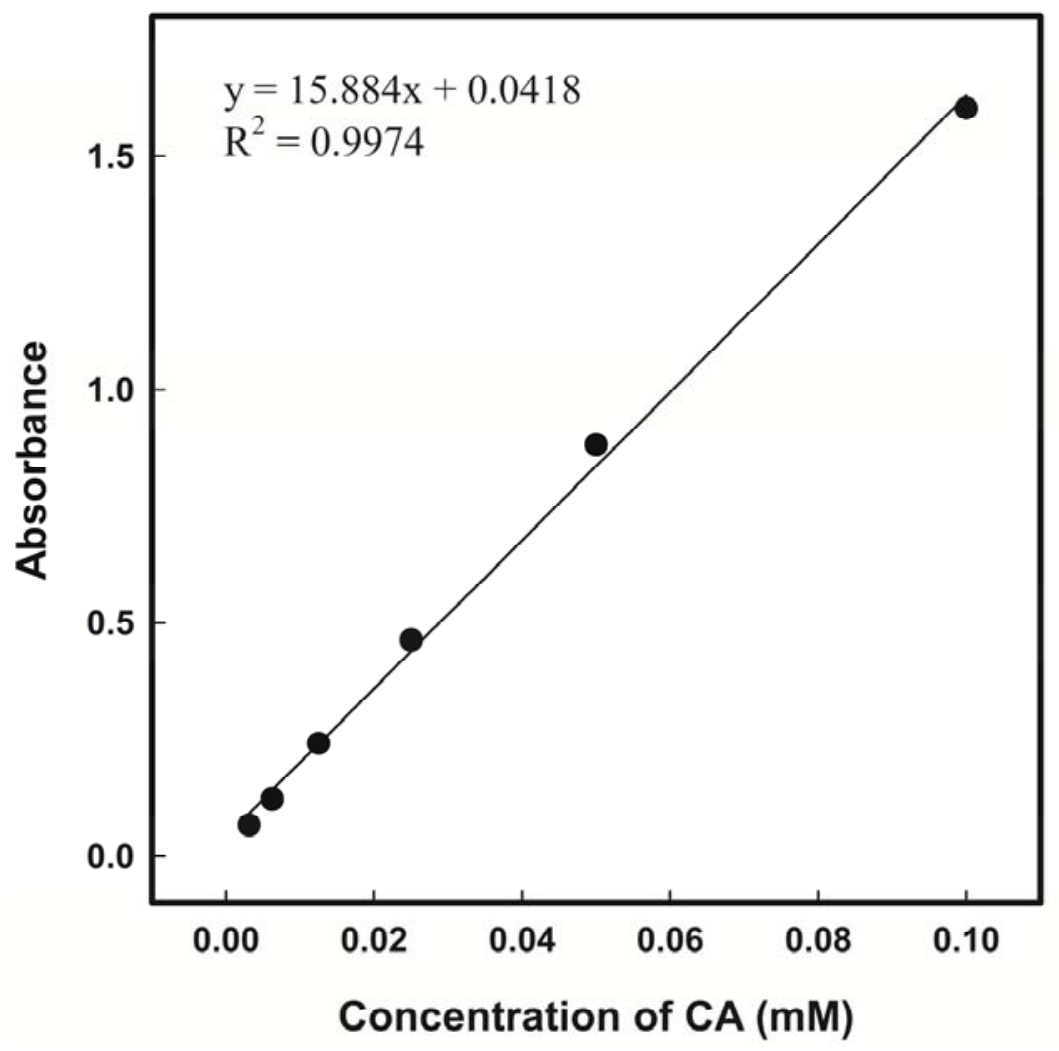


Fig.3 The molar extinction coefficient of CA residue of cinnamic acid-gelatin (type B) conjugate (CA-GelB).

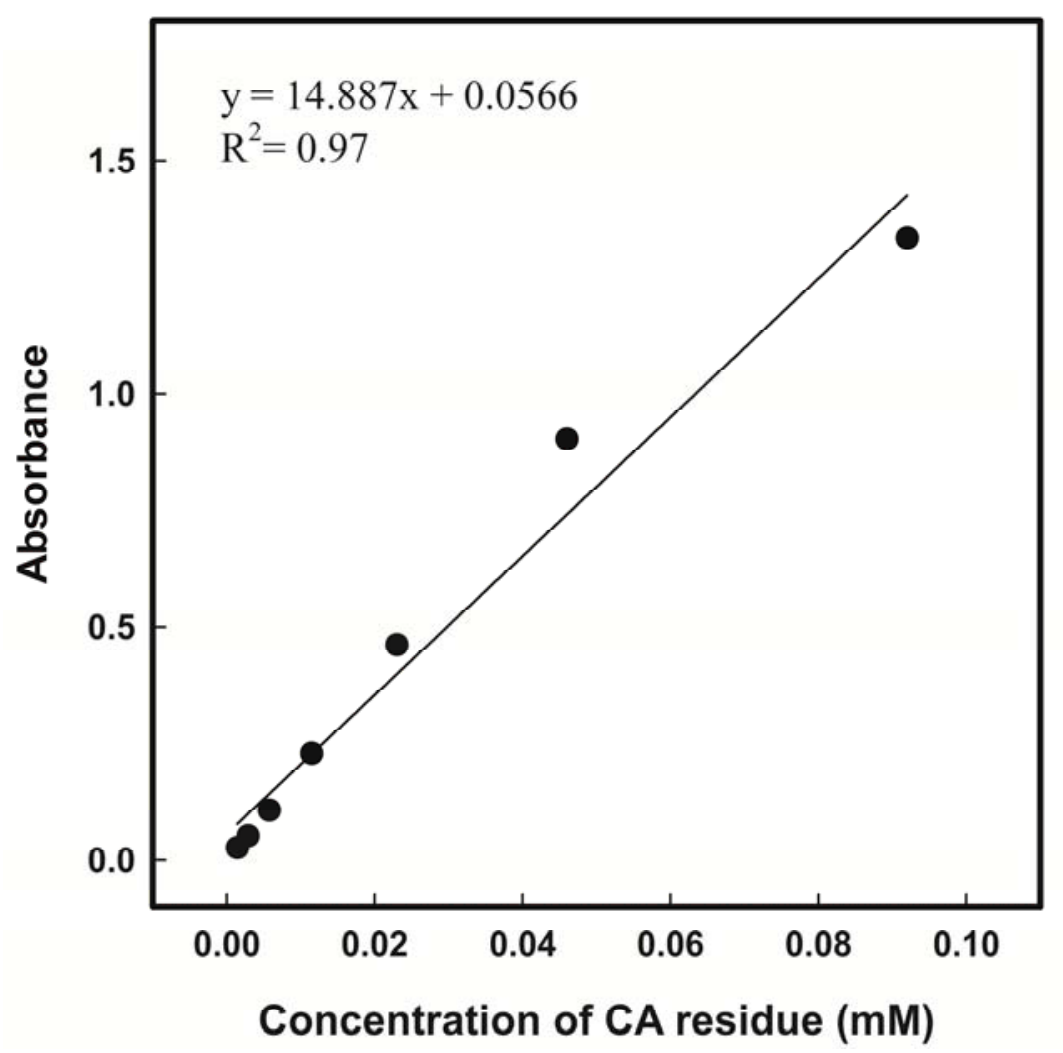


Fig.4 The calibration curve of doxorubicin (DOX) at pH 3.0.

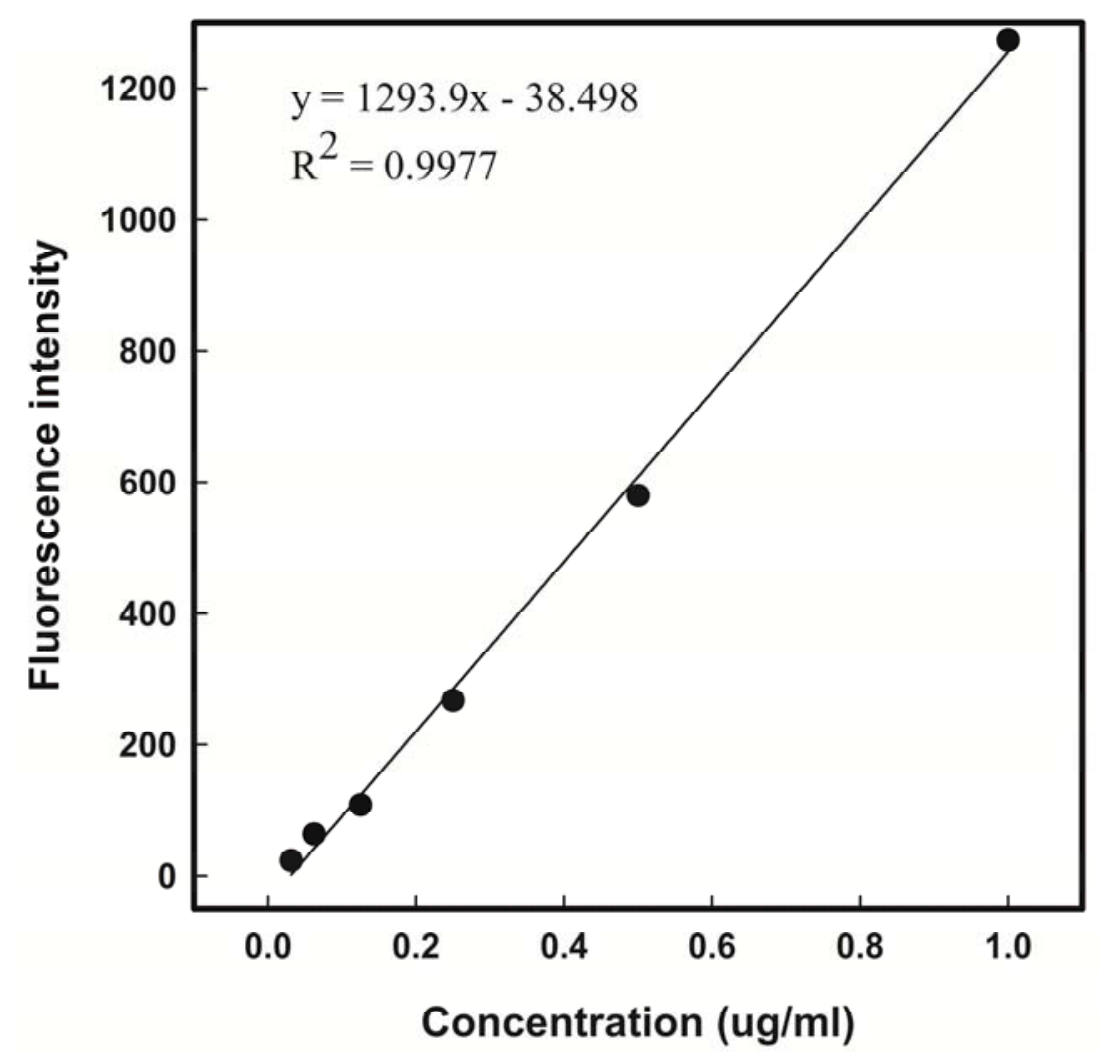


Fig.5 The calibration curve of DOX at pH 5.0.

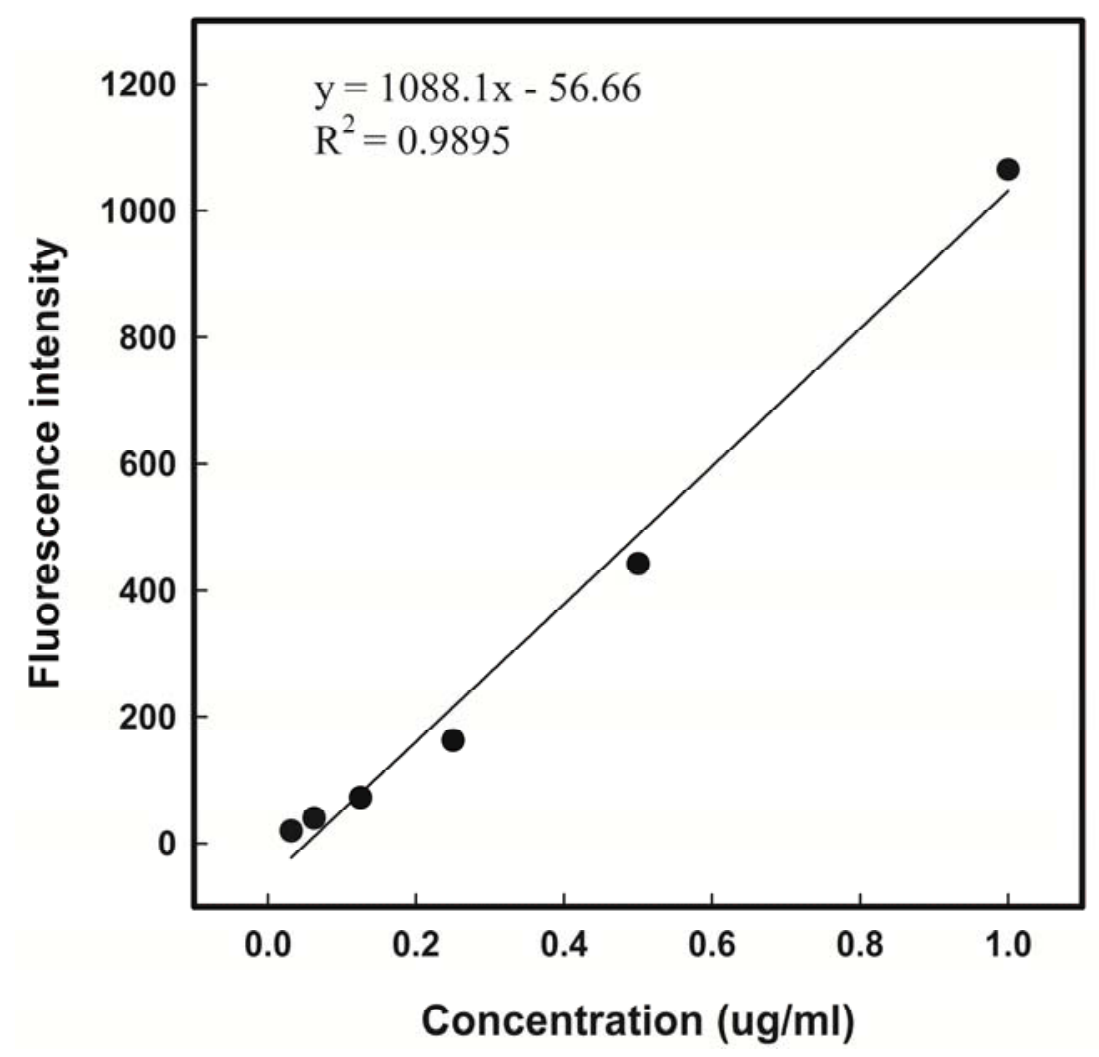


Fig.6 The calibration curve of DOX at pH 7.4.

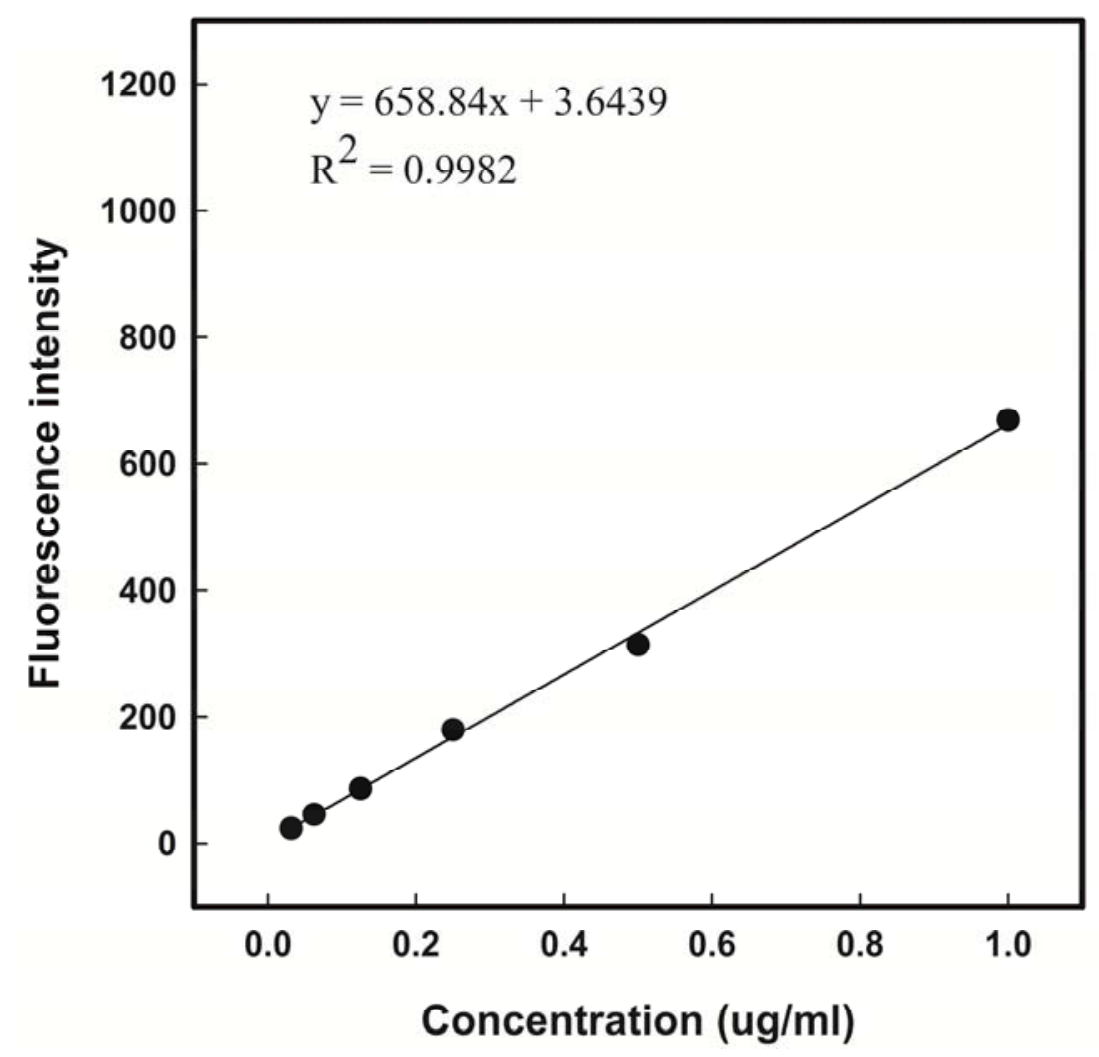

